POLLACK PERIODICA

An International Journal for Engineering and Information Sciences

DOI: $10.1556 / 606.2017 .12 .2 .4$

Vol. 12, No. 2, pp. 43-51 (2017)

www.akademiai.com

\title{
STRENGTHENING OF AXIALLY LOADED CIRCULAR COLUMNS
}

\author{
Attila VÁRDAI \\ Department of Structural Engineering, Budapest University of Technology and Economics \\ Department for Building Services, ÉMI-TÜV SÜD Ltd \\ Dugonics str. 11, H-1043 Budapest, Hungary, e-mail: vardai.attila@emi-tuv.hu
}

Received 31 December 2016; accepted 2 March 2017

\begin{abstract}
The application of a deformation-based analytical approach is presented in this paper to calculate the strength-increase of axially loaded circular columns, strengthened with fiber reinforced polymer and reinforced concrete jackets.

A short introduction of the calculation methodology is presented and the adopted basic assumptions are briefly explained. Through a trial-and-error type iterative procedure the magnitude of confining stresses and the confined strength of core material are determined, based on the compatibility of lateral deformations of the core column and the jacket-wall.

The accuracy of the proposed model for circular sections is demonstrated with a comparison with 149 test results.
\end{abstract}

Keywords: Strengthening, Jacketing, Circular column, Triaxial stress, Compatibility

\section{Introduction}

Strengthening of columns by means of jacketing is a frequently used technique, with a long term experience of application in practice [1]. In spite of its worldwide use, no generally applicable and accepted theory is available to analyze the behavior of jacketed columns.

The available calculation methods are limited to analyze the ultimate state behavior of strengthened specimen and they are suitable only for specific use e.g. to analyze Fiber Reinforced Polymer (FRP) confined columns.

An approach has been recently developed (see [2] and [3]) to calculate the strengthincrease of the core material of (FRP) and Reinforced Concrete (RC) jacketed square 
columns at any selected stress level. The theoretical background of the proposed method is explained in details in [2] and [3], comparison with previous analytical approaches and experimental results (for square columns) are available in [2] and [4].

This paper focuses on the applicability of the method on axially loaded circular columns as the same approach is considered suitable to accurately predict the strengthincrease, independently from the shape of a cross-section.

After discussing theoretical considerations and the calculation procedure of the approach itself (section 2), the modeling and importance of material damage is highlighted (section 3). A large database of experimental results is evaluated to verify accuracy (section 4). The final section summarizes the findings.

\section{Theoretical considerations}

Due to the Poisson-effect, the compressed material shortens axially and expands in lateral directions. The failure of uniaxially compressed concrete is generated by this lateral deformation and corresponding lateral tensile stresses.

Jackets restrain lateral deformation of the core material; therefore, delay failure. As confinement is provided, the strength and ductility of jacketed material increase, and internal (so called confining) pressure will be developed on the jacket-wall (Fig. 1). The jacket has to have enough capacity to resist these internal pressures to be able to adequately confine the core material.

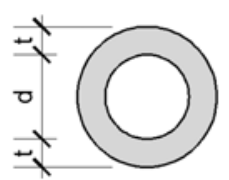

a) geometry

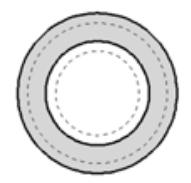

b) deformation

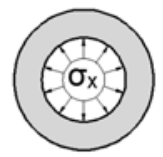

c)stresses

Fig. 1. Jacket-deformation and confining stresses

To estimate lateral deformation, the generalized Hooke's law is commonly used. However, to take into account the material nonlinearity of concrete, the original form of the equation has to be slightly modified. The material constants can be replaced by stress-dependent functions of variables [5] to consider material damage during loading. The modified form of the generalized formula to determine lateral strain is written as follows in eq. (1):

$$
\varepsilon_{x}=\frac{\sigma_{x}-v\left(\sigma_{y}+\sigma_{z}\right)}{E} \rightarrow \frac{\sigma_{x}-v(\sigma)\left(\sigma_{y}+\sigma_{z}\right)}{E_{(\sigma)}},
$$

where $\varepsilon_{x}$ is the lateral expansion; $\sigma_{x}, \sigma_{y}$ and $\sigma_{z}$ are the stresses in the $x, y$ and $z$ direction respectively; $v$ and $v_{(\sigma)}$ are the constant and stress-dependent values of Poisson's raito, 
respectively; $E$ and $E_{(\sigma)}$ are the constant and stress-dependent values of the modulus of elasticity (or deformational modulus).

The proposed model is based on the compatibility of lateral expansion of the core material from Poisson-effect, and lateral deformation of jacket-wall due to confining pressure (Fig. 2).

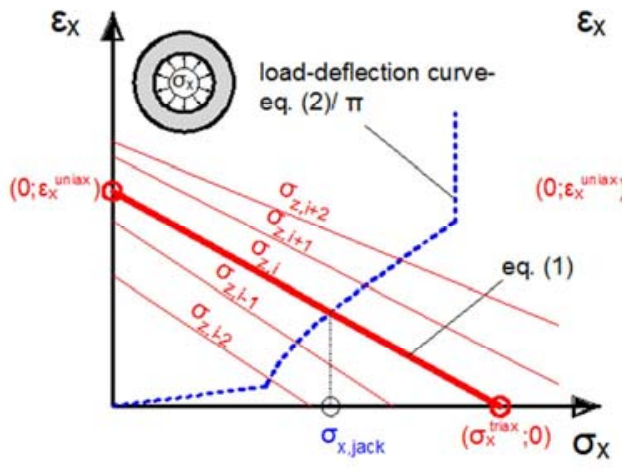

a) RC jackets

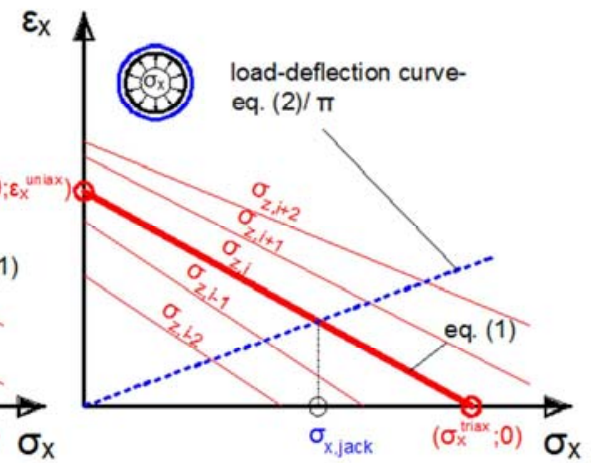

b) FRC jackets

Fig. 2. Jacket-deformation and confining stresses

In case of square columns the determination of distribution of confining stresses is complex, as the jacket is subjected to eccentric tension; therefore, at the middle part of the jacket-wall, considerable flexural deformation takes place [3]. Due to additional flexural deformation, the confinement is reduced in the mid-wall zones.

In case of circular sections these additional flexural deformations do not exist (or this effect can be neglected in the calculations), and therefore, only the elongation due to centric tension is to be investigated. The elongation of jacket-wall $\left(\varepsilon_{\text {jack }}\right)$, generated by tensile force is calculated as follows in (2):

$$
\varepsilon_{\text {jack }}=\frac{n_{\text {jack }}}{E A}
$$

where $n_{\text {jack }}$ is the tensile force and $E A$ is the axial stiffness of the jacket-wall.

As tension is considered constant at the investigated cross-section, constant internal pressure is assumed. This latter assumption highly simplifies the adopted equations for calculation. From constant confining pressure the tensile force in the jacket-wall is computed in (3) as:

$$
n_{j a c k}=\sigma_{x} \cdot r_{c o l} \cdot b_{j a c k}
$$

$\sigma_{x}$ is the lateral (confining) pressure; $r_{c o l}$ is the radius of the jacketed column; $b_{j a c k}$ is the breadth of the investigated section of the jacket. 
Based on geometrical considerations the dependence between the strains of the jacket and the core, namely the compatibility requirement of circular sections can be written in (4) as:

$$
\varepsilon_{\text {jack }}=\varepsilon_{x} \cdot \pi
$$

where $\varepsilon_{j a c k}$ is the elongation of the jacket from tension, according to eq. (2) and $\varepsilon_{x}$ is the lateral expansion, according to eq. (1).

The deformation due to Poisson-effect can be graphically represented in a lateral strain $\left(\varepsilon_{x}\right)$ versus lateral stress $\left(\sigma_{x}\right)$ coordinate system, as shown in Fig 2. For each stresslevel $\left(\sigma_{z}\right)$ the relationship between strains and stresses (continuous lines in Fig. 2) is defined by the modified Hooke's law (1). The two endpoints of the (continuous) lines are representing the uniaxial stress-state $\left(\sigma_{x}=0 \rightarrow 0 ; \varepsilon_{x}{ }^{\text {uniax }}\right)$ and the uniaxial deformationstate $\left(\varepsilon_{x}=0 \rightarrow \sigma_{x}^{\text {triax }}\right)$, respectively. The first case symbolizes the core column without any confinement, while the latter case is purely theoretical when absolutely no deformation is experienced; therefore, it represents a completely rigid jacket. Any actual stress-state for real strengthening problems (namely jackets with finite rigidity) will be located in between these two dedicated points (as also indicated in Fig. 2).

In the same $\sigma_{x}-\varepsilon_{x}$ coordinate system the load-deflection curve of the jacket-wall can also be displayed (dashed curves), by interpreting the confining stresses (internal pressures) as load, and transforming the calculated elongation of the jacket-wall- $\varepsilon_{j a c k}$ (with the re-arrangement of (4) into lateral expansion- $\varepsilon_{x}$.

It is indicated in Fig. 2 that any stress level can be investigated with the proposed approach; therefore, the criteria of Serviceability Limit Stress state (SLS) also can be evaluated. The existing analytical models [6]-[12] are suitable only to determine failure conditions at Ultimate Limit State (ULS).

In Fig. 2 the physically only possible confining stress intensity for a selected axial stress level of the core $\left(\sigma_{z}\right)$ is located at the intersection of the load-deflection curve of the jacket-wall and the 'curve for stress-states' defined by the Hooke's law.

It is also indicated, that the same basic considerations and calculation procedure can be applied for FRP and RC jackets; however, for RC jackets, the determination of strains have to be based on the effective axial stiffness $\left(E A_{e f f}\right)$, with regard to the stiffness-reduction due to cracking with increasing tension.

\section{Damage and utilization of material}

To get calculation results accurate enough for practical application, the material nonlinearity has to be considered for both the core material and the RC jackets.

Experiments with uniaxially compressed cylinders showed that the Poisson's-ratio, despite the recommendations of most international codes, is not constant ([13] and [14]). As the load increases, micro-, and after approximately $80 \%$ utilization (visible) macro- cracks develop, and therefore, at high level of utilization the lateral expansion would not be proportional to the axial shortening of the specimen. 
For calculation purposes the proposed model adopts Ottosen's equation [15] for core material, with the ultimate value of Poisson's-ratio at failure as 1.0 (Fig. 3), following [13] and [14].

$$
\begin{array}{ll}
v_{(\sigma)}=v_{0}=0.2, & \text { for } \sigma_{z} / f_{c c}<0.8, \\
v_{(\sigma)}=v_{u}-\left(v_{u}-v_{0}\right) \sqrt{1-\left(\frac{\sigma_{z} / f_{c c}}{v_{0}}\right)^{2}}, & \text { for } \sigma_{z} / f_{c c} \geq 0.8
\end{array}
$$

where $v_{(\sigma)}$ is the stress-dependent function of Poisson's ratio; $v_{0}$ and $v_{u}$ are the initial and ultimate values of the Poisson's ratio respectively; $\sigma_{z} / f_{c c}$ is the utilization of the core with respect to the confined strength.

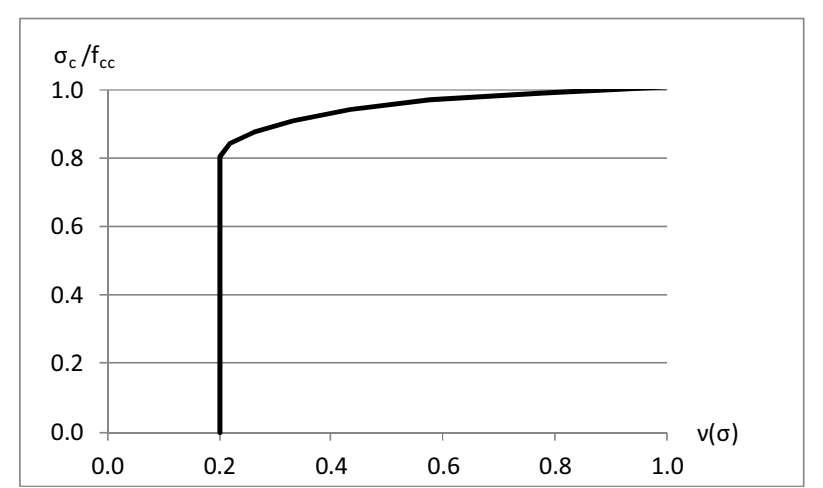

Fig. 3. Influence of the utilization on the Poisson's-ratio [13] and [15]

As (5) shows, the calculated utilization is based on the confined strength $\left(f_{c c}\right)$ of the core material. To determine the confined strength, the equations of EUROCODE 2 are adopted (Fig. 4)

$$
\begin{aligned}
& f_{c c}=f_{c, 0} \cdot\left(1.000+0.5 \cdot \sigma_{x} / f_{c, 0}\right), \quad \text { for } \quad \sigma_{x} \leq 0.05 \cdot f_{c, 0}, \\
& f_{c c}=f_{c, 0} \cdot\left(1.125+2.5 \cdot \sigma_{x} / f_{c, 0}\right), \text { for } \quad \sigma_{x}>0.05 \cdot f_{c, 0},
\end{aligned}
$$

where $f_{c c}$ and $f_{c, 0}$ are the confined and the uniaxial compressive strength of the core, respectively.

The confined strength is based on the confining stresses $\left(\sigma_{x}\right)$; therefore, an iterative calculation is required to reach an adequate solution. 


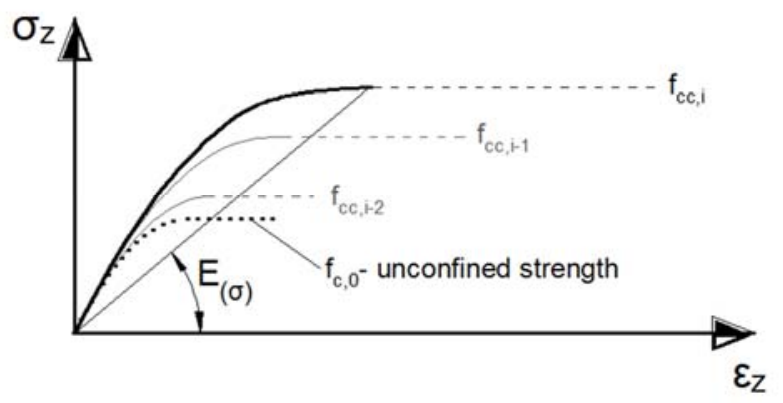

Fig. 4. Adopted stress-strain diagram of confined concrete (EUROCODE 2)

The stress-dependent deformational modulus (secant modulus, $E_{(\sigma)}$ ) from (1) can be derived from any non-linear stress-strain diagram. For the proposed model the parabolarectangle diagram (7) for confined concrete is adopted from EUROCODE 2 (Fig. 4)

$$
\begin{array}{ll}
\sigma_{c, z}=f_{c c} \cdot\left(1-\left(1-\frac{\varepsilon_{c, z}}{\varepsilon_{c 2, z}}\right)^{n}\right), & \text { for } 0 \leq \varepsilon_{z, c} \leq \varepsilon_{c 2, c}, \\
\sigma_{c, z}=f_{c c}, & \text { for } \varepsilon_{c 2, c} \leq \varepsilon_{z, c} \leq \varepsilon_{c u 2, c} .
\end{array}
$$

In case of RC jackets the stiffness of cracked concrete has to be evaluated accurately to model the structural behavior correctly at high stress-level as well.

The EUROCODE 2 offers a simplified method to estimate the effective axial and flexural stiffness after cracking, where even tension stiffening $(\zeta)$ is considered. The adopted equation for calculation in the proposed model (8):

$$
E A_{e f f}=\frac{E_{c} \cdot A_{I} \cdot E_{S} \cdot A_{S}}{\zeta \cdot E_{c} \cdot A_{I}+(\zeta-1) \cdot E_{S} \cdot A_{S}},
$$

where $E A_{\text {eff }}$ is the effective axial stiffness of the jacket, $E_{c} A_{I}$ is the axial stiffness of the uncracked section; $E_{s} A_{s}$ is the axial stiffness of the applied stirrups; $\zeta$ is the constant to take tension stiffening into account.

As the aforementioned damage model describes, even small increase of load results in rapid growth of confining pressure at stress-levels near failure. After confined strength is reached, the lateral pressure can be increased until the deformational capacity of the core $\left(\varepsilon_{c u 2, c}\right)$, or the ultimate tensile resistance of the jacket $\left(n_{R, j a c k}\right)$ is exploited.

In case of 'weak jackets' premature tensile failure of jacket-wall is observed before the confined strength of a column can fully develop.

The proposed model focuses on the load-bearing resistance of the core material; the capacity of the jacket-wall has to be investigated individually.

It is assumed in the model that any further increment of internal pressure would not be effective and would not result in further strength-increase when the stress-level 
reaches the confined strength of the core material. With this assumption the descending branch of the stress-strain diagram (or the plastic plateau of the simplified material models - Fig. 4 and (7)) is neglected; therefore, the increase of ductility due to jacketing is not investigated.

\section{Comparison with experimental results}

To verify the accuracy and applicability of the proposed model, a large database of 149 experimental results ([6], [12]) is evaluated.

As research topics regarding FRP confined specimens has become popular recently, the majority (146 elements) of the evaluated test specimens are about FRP strengthened columns (cylinders), while only a very small portion (3 elements) focuses on RC jacketed specimens.

The complete database of RC-jacketed specimens is filtered to only three tests, were the whole section (the core and jacket-wall simultaneously) was loaded to avoid the effect of uncertain load transfer between the core and the jacket [7]. The distribution of axial compression between the core and the jacket is taken into account by basic equilibrium equations based on the ultimate resistance of longitudinal reinforcement, core material and jacket concrete.

Besides providing confinement to the core, $\mathrm{RC}$ jackets might be capable to take axial loads directly and due to considerable section enlargement of the original column $\mathrm{RC}$ jacketing even reduces the sensitivity to buckling failure.

In case of FRP jacket these phenomena do not have any influence on the evaluation of test results as the slender FRP jackets are not capable to take axial compression, nor they help against buckling.

Comparisons of the model predictions and empirical findings are shown in Fig. 5. The available database usually presents the observed strength-increase $\left(f_{c c} / f_{c \mathrm{co}}\right)$ in case of FRP strengthened columns; however, for RC jacketing typically the axial compressive force is given in $N_{R}[\mathrm{kN}]$. Fig 5 displays the results in both systems.

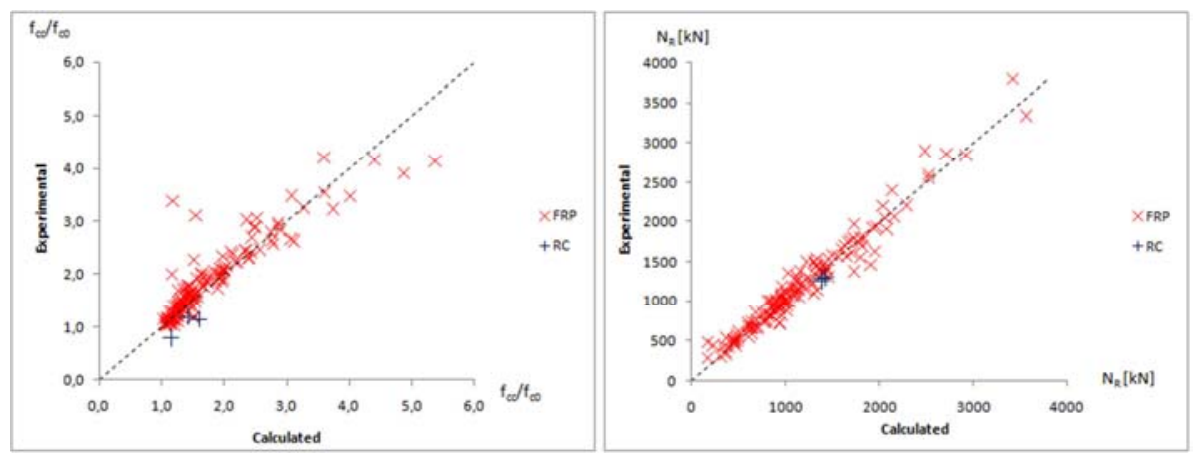

a)

b)

Fig. 5. Comparison of a) experimental and calculated strength-increase and b) ultimate capacity 
Significant strength-increase can be observed in case of some FRP jackets (Fig. 5a), even more than four times of the unconfined strength of concrete specimens can be achieved with special products.

According to the current regulations, strengthening can be designed only to double the existing capacity of a structure. In any other cases loads shall be transferred to an independent structure to avoid overloading. Within the range of standard limitations the results of the proposed calculation method are in good agreement with the experiments, the average absolute error is found to be $7.8 \%$.

The accuracy to predict the ultimate capacity of a strengthened element is considered satisfactory for all elements, as indicated in Fig. 5b. The average absolute error of the proposed model, when the complete database is considered is found to be $8.93 \%$ (for the three experiments with RC jackets $9.09 \%$ can be computed).

Furthermore, the estimation provided by the introduced approach is usually (in the two third of all the evaluated cases) conservative. The safety factors of code-based design completely cover the experienced uncertainties; therefore, the proposed model is considered applicable for practical use.

\section{Conclusion}

No generally accepted theoretical model is available to analyze the behavior of FRP and RC jacketed columns. Several analytical methods have been developed for specific use; however, their applicability for general use is highly limited.

The theoretical bases of a newly developed deformation-based method are explained to estimate the strength-increase of an axially compressed circular column, strengthened with FRP or RC jackets. The new model is capable to estimate the strength-increase of the core material by taking the compatibility of lateral expansion of the core due to the Poisson-effect and the lateral deformation of jacket-wall generated by confining stresses into account.

The assumptions are not limited only to ultimate limit state calculations; therefore, the serviceability conditions can also be investigated. Development of confining stresses can be determined during the complete load history of a structure. The analysis and evaluation of deformation are required at ultimate limit state calculations, too, to predict accurately the strength-increase due to confinement.

Previous studies show that the new approach gives adequate estimations for square columns. Validation for circular columns is presented in this paper.

A database of available experiments with circular columns was used to validate the theoretical predictions. The analysis resulted in good agreement with the estimations of the proposed method, the average absolute error is found to be $8.93 \%$ for all 149 evaluated elements.

It is concluded that the basic assumptions of the approach can be generally adopted for both square and circular columns, and the method is applicable to determine the strength-increase of strengthened columns, confined with FRP or RC jackets. 


\section{Acknowledgements}

The Author acknowledges the technical and financial support of the Department of Structural Engineering of Budapest University of Technology and Economics and the ÉMI-TÜV SÜD Kft.

\section{References}

[1] Bordea S. Strengthening of MRF RC frames located in seismic areas with BRB and FRP, Pollack Periodica, Vol. 3, No. 3, 2008, pp. 45-57.

[2] Várdai A., Bódi I., Madaras B. A new approach for column jacket design, Proceedings of FIB Symposium, Cape Town, South Africa, 21-23 November, 2016, article no. 251.

[3] Várdai A., Bódi I., Madaras B., Design of RC jacketing, Part 1, Introduction of design methods, (in Hungarian) Vasbetonépités, Vol. XVIII, No. 2, 2016, pp. 28-33.

[4] Várdai A., Bódi I. Madaras B. Design of RC jacketing, Part 2, Evaluation of design methods, (in Hungarian) Vasbetonépítés, Vol. XVIII, No. 3, 2016, pp. 52-57.

[5] Bouafia Y., Smahi R., Dumontet H., Kachi M. S. Modeling the behavior of concrete by damage mechanics with a Poisson's ratio variable, Procedia Materals Science, Vol. 3, 2014, pp. 714-719.

[6] Takeuti A. R., Hanai J. B., Mirmiran A. Preloaded RC columns strengthened with highstrength concrete jackets under uniaxial loading, Materials and Structures, Vol. 41, 2008, pp. 1251-1262.

[7] Duratna P., Bujnak J., Bouchair A. Behavior of steel-concrete composite trusses, Pollack Periodica, Vol. 8, No. 3, 2013, pp. 23-28.

[8] Zhao Y., Zhang D., Shen S., Ueda T. Axial loading capacity of concrete-jacketed RC columns with pre- and post-corrosion damage, Structural Concrete, Vol. 17, No. 3, 2016, pp. 355-364.

[9] Sirimontree S., Witchayangkoon B., Lertpocasombut K. Strengthening of reinforced concrete column via ferrocement jacketing, American Transactions on Engineering\& Applied Sciences, Vol. 4, No. 1, 2015, pp. 39-47.

[10] Campione G., Fossetti M., Giacchino C., Minafo G. RC columns externally strengthened with RC jackets, Materials and Structures, Vol. 47, No. 10, 2014, pp. 1715-1728.

[11] Faustino P., Chastre C., Paula R. Design model for square RC columns under compression confined with CFRP, Composites, Part B, Engineering, Vol. 57, 2014, pp. 187-198.

[12] Csuka B. Axially loaded FRP confined reinforced concrete cross-sections, PhD Thesis, Budapest University of Technology and Economics, 2012.

[13] Palotás L. Theory of reinforced concrete, Akadémiai Kiadó, Budapest, 1973.

[14] Kato K. Microcrakcs, deformation and properties of plain concrete, Proceedings of $5^{\text {th }}$ International Congress on Fracture, Cannes, France, 29 March - 3 April, 1981, pp. 2275-2280.

[15] Ottosen N. S., Constituve model for short-time loading of concrete, Journal of the Engineering Mechanics Division ASCE, Vol. 105, 1979, pp. 127-141. 